\title{
Recuperação no sistema solo-planta de nitrogênio derivado da adubação verde aplicada à cultura do repolho
}

\author{
Ednaldo da Silva Araújo(1), José Guilherme Marinho Guerra(1), José Antônio Azevedo Espindola(1), \\ Segundo Urquiaga( ${ }^{(1)}$, Robert Michael Boddey(1), Luiz Aurélio Peres Martelleto(2) e Bruno José Rodrigues Alves(1) \\ (1)Embrapa Agrobiologia, BR 465, Km 7, CEP 23890-000 Seropédica, RJ. E-mail: ednaldo@cnpab.embrapa.br, gmguerra@cnpab.embrapa.br, \\ jose@cnpab.embrapa.br, urquiaga@cnpab.embrapa.br, bob@cnpab.embrapa.br, bruno@cnpab.embrapa.br (2)Empresa de Pesquisa Agropecuária do \\ Estado do Rio de Janeiro, Estação Experimental de Seropédica, BR 465, Km 7, CEP 23890-000 Seropédica, RJ. E-mail: luizmarte@hotmail.com
}

Resumo - O objetivo deste trabalho foi determinar a eficiência de recuperação, no sistema solo-planta, do nitrogênio derivado da adubação verde aplicada à cultura de repolho (Brassica oleracea). O experimento foi dividido em duas etapas: a primeira consistiu da produção de palhada de feijão-de-porco (Canavalia ensiformis), mucuna-cinza (Mucuna cinereum), e sorgo (Sorghum bicolor), em substrato enriquecido com ${ }^{15} \mathrm{~N}$. A segunda etapa consistiu da aplicação das palhadas marcadas com ${ }^{15} \mathrm{~N}$, em cobertura nos canteiros com repolho. Os tratamentos consistiram de: palha fresca de feijão-de-porco; palha fresca de mucuna-cinza; palha fresca de sorgo; mistura das palhas de mucuna, feijão-de-porco e sorgo a 1:1:1; e controle sem adubação verde. A recuperação de N no sistema solo-planta foi influenciada pelo tipo de palhada utilizado, e a eficiência de recuperação do $\mathrm{N}$ derivado da palhada de leguminosa variou de 9 a 16\%. O tratamento com palha de feijão-de-porco é o que apresenta maior eficiência de recuperação e, portanto, a melhor sincronia da oferta de nitrogênio pela decomposição da palhada com a demanda pela cultura do repolho.

Termos para indexação: adubo verde, dinâmica de nitrogênio, hortaliças, isótopos de ${ }^{15} \mathrm{~N}$.

\section{Recovery in the soil-plant system of nitrogen from green manure applied on cabbage crop}

\begin{abstract}
The objective of this work was to determine, in the soil-plant system, the recovery efficiency of $\mathrm{N}$ derived from green manure applied on cabbage (Brassica oleracea) crop. The experiment was divided into two stages: the first one consisted of the straw production of jack bean (Canavalia ensiformis), velvet bean (Mucuna cinereum), and sorghum (Sorghum bicolor), in substrate enriched with ${ }^{15} \mathrm{~N}$. The second stage consisted of the application of ${ }^{15} \mathrm{~N}$-labeled green manure on the cabbage beds. Treatments consisted of: fresh residues of jack bean; fresh residues of velvet bean; fresh residues of sorghum; mixture of residues of jack bean, velvet bean, and sorghum at 1:1:1; and control without green manure addition. The $\mathrm{N}$ recovery in the soil-plant system was influenced by the green manure species used, and the recovery efficiency of the $\mathrm{N}$ derived from the green manure legumes varied from 9 to $16 \%$. The jack bean treatment shows a greater recovery efficiency of nitrogen and, therefore, the best synchrony of $\mathrm{N}$ supply, by straw decomposition, with the cabbage crop demand.
\end{abstract}

Index terms: green manure, nitrogen dynamics, vegetables, isotope ${ }^{15} \mathrm{~N}$.

\section{Introdução}

$\mathrm{O} \mathrm{N}$ fornecido na forma de adubo verde pode ser absorvido pela cultura, permanecer na forma de resíduos, ser imobilizado pela biomassa microbiana do solo e, ainda, ser perdido por lixiviação de nitrato ou volatilização de amônia (Amado et al., 2002; Lara Cabezas et al., 2004). Dessa forma, a eficiência da recuperação do $\mathrm{N}$ pelas culturas se relaciona com o sincronismo entre a liberação de $\mathrm{N}$ dos adubos verdes e a absorção pelas plantas (Fontanétti et al., 2006).

Observa-se, na literatura, carência de informações sobre a eficiência de recuperação do $\mathrm{N}$ derivado da adubação verde e do destino do $\mathrm{N}$ no sistema soloplanta. De-Polli et al. (1996) destacam a necessidade de estudos sobre a eficiência de recuperação do $\mathrm{N}$ originário da adubação verde, principalmente com uso do isótopo ${ }^{15} \mathrm{~N}$. O conhecimento desse valor pode auxiliar na elaboração de estratégias de manejo para otimizar o $\mathrm{N}$ derivado da adubação verde e, também, na recomendação da dose de $\mathrm{N}$ do adubo verde para uma determinada cultura de interesse econômico.

Perin et al. (2004) observaram que o aproveitamento do $\mathrm{N}$ derivado de Crotalaria juncea, pela cultura do brócolis, foi de cerca de $10 \%$. Em cultura da cana-de-açúcar, Ambrosano et al. (2011) observaram 
que a recuperação do $\mathrm{N}$ derivado do adubo verde foi de cerca de $20 \%$, considerando-se duas safras, em sistema de pré-cultivo de $C$. juncea. Para essa mesma espécie de adubo verde, Silva et al. (2006) observaram que a recuperação de $\mathrm{N}$ pela cultura do milho foi de cerca de $15 \%$.

A dinâmica do $\mathrm{N}$ derivado do adubo verde pode ser estudada com uso do isótopo ${ }^{15} \mathrm{~N}$, de forma indireta (Urquiaga \& Zapata et al., 2000) e direta (Cueto-Wong et al., 2001; Ambrosano et al., 2003). O método direto consiste em duas etapas, na primeira, efetuase a marcação dos adubos verdes com ${ }^{15} \mathrm{~N}$. Para isso, cultiva-se a espécie para adubação verde em substrato que contém ${ }^{15} \mathrm{~N}$. Na segunda etapa, o material vegetal marcado é aplicado como adubo verde para a cultura em teste. A partir da marcação com ${ }^{15} \mathrm{~N}$, observada após a colheita da cultura, estima-se o $\mathrm{N}$ derivado do adubo verde.

O método direto, além da determinação da transferência de $\mathrm{N}$ do adubo verde para a cultura, permite avaliar toda dinâmica de $\mathrm{N}$ derivado do adubo verde no sistema solo-planta. Contudo, na literatura há escassez de dados com uso dessa técnica, principalmente para estudos de dinâmica de $\mathrm{N}$ em sistema de produção de hortaliças. As hortaliças, de modo geral, são cultivadas em condições de alto teor de matéria orgânica e N no solo (Filgueira, 2003). Assim, a adubação verde é uma técnica bastante utilizada nesses sistemas e requer estudos para aumentar sua eficiência e contribuir para o aumento da fertilidade do solo e redução dos custos de produção.

O objetivo deste trabalho foi determinar a eficiência de recuperação, no sistema solo-planta, do $\mathrm{N}$ derivado da adubação verde aplicada à cultura do repolho.

\section{Material e Métodos}

O estudo foi realizado na área experimental da Embrapa Agrobiologia, Seropédica, RJ, e foi divido em duas etapas. Na primeira, foram produzidos feijão-de-porco, mucuna-cinza e sorgo, marcados com ${ }^{15} \mathrm{~N}$, em condições de casa de vegetação. A segunda etapa foi realizada em condições de campo e consistiu da aplicação do adubo verde, marcado com ${ }^{15} \mathrm{~N}$, à cultura do repolho (Brassica oleracea L. var. Capitata). O estudo de campo foi conduzido na Fazendinha Agroecológica, Km 47, Baixada Fluminense, Município de Seropédica, RJ (22\% $48^{\prime} \mathrm{S}, 43^{\circ} 41^{\prime} \mathrm{W}$, altitude $\left.33 \mathrm{~m}\right)$.
O clima da região é do tipo Aw da classificação de Köppen e caracteriza-se pela ocorrência de chuvas frequentes e temperaturas elevadas, no verão, e pelo inverno pouco rigoroso e geralmente seco. As médias anuais são de cerca de $24^{\circ} \mathrm{C}$ e de $1.213 \mathrm{~mm}$ de temperatura média e precipitação pluvial, respectivamente (Carvalho et al., 2006).

A produção do adubo verde foi realizada em condições de casa de vegetação, em vasos com cerca de $40 \mathrm{~kg}$ de substrato $(50 \%$ de areia lavada e $50 \%$ de vermiculita, v/v). Foram utilizadas as seguintes espécies: feijão-de-porco [Canavalia ensiformis (L) DC.], mucuna-cinza [Mucuna cinereum Piper \& Tracy)] e sorgo [Sorghum bicolor (L)]. O plantio foi realizado em casa de vegetação, da Empresa de Pesquisa Agropecuária do Estado do Rio de Janeiro, em março de 2009. No momento do preparo do substrato, foram adicionados todos os nutrientes, com exceção de N. Nessa ocasião, a adubação consistiu de $0,1 \mathrm{~g} \mathrm{~kg}^{-1}$ de FTE (Nutriplan, Cascavel, PR), 3,4 $\mathrm{g} \mathrm{kg}^{-1} \mathrm{de}$ superfosfato simples e $0,5 \mathrm{~g} \mathrm{~kg}^{-1}$ de sulfato de potássio. Foram utilizados 22 vasos por cultura. A semeadura foi feita com seis sementes por vaso, para as leguminosas, e 18 sementes por vaso, para o sorgo. Após o desbaste, permaneceram quatro plantas de leguminosas e 12 plantas de sorgo.

O nitrogênio foi aplicado em cobertura, divido em quatro doses ( $1 \mathrm{~g}$ de $\mathrm{N}$ por vaso, por dose) aos 11, 18, 34, e aos 41 dias após a semeadura (DAS). Nas duas primeiras e na última aplicação, o $\mathrm{N}$ foi adicionado na forma de solução de ureia com $1,67 \%$ de átomos de ${ }^{15} \mathrm{~N}$, enquanto na terceira aplicação, em que foi constatada a presença de nódulos nas raízes das leguminosas, foi utilizada a solução de ureia com $3 \%$ de átomos de ${ }^{15} \mathrm{~N}$. Aos 13 DAS, também foi aplicada uma solução de micronutrientes (Franco \& Dobereiner, 1967), a $1 \mathrm{~mL} \mathrm{~kg}^{-1}$ de substrato, e cloreto de potássio na dose de $1,0 \mathrm{~g}$ por vaso, aos $18 \mathrm{DAS}$.

Procedeu-se à semeadura da cultivar Seisho de repolho 33 dias após a semeadura das leguminosas e de sorgo em casa de vegetação. A semeadura foi realizada em bandejas de poliestireno expandido, com 200 células com substrato orgânico (humos de minhoca). Esse procedimento visou à produção de mudas de repolho de forma a coincidir o período de transplantio com a época de coleta dos adubos verdes.

Aos 30 DAS do repolho, ocorrida em maio de 2009, realizou-se o transplantio para Argissolo, textura 
média, com as seguintes características químicas, determinadas conforme Claessen (1997): $\mathrm{pH}$ em água, 6,0; $\mathrm{Al}, 0,0, \mathrm{Ca}^{+}, 2,6$ e $\mathrm{Mg} 1,5 \mathrm{cmol}_{\mathrm{c}} \mathrm{dm}^{-3} ; \mathrm{P}$ e K 50 e $280 \mathrm{mg} \mathrm{dm}^{-3}$, MO 13,3 $\mathrm{g} \mathrm{kg}^{-1}$. A área foi arada e gradeada com posterior encanteiramento com microtrator e enxada rotativa.

Nos canteiros, as mudas foram espaçadas em $0,4 \times 0,6 \mathrm{~m}$, em microparcelas de $1,6 \mathrm{~m}^{2}$, que continham, cada uma, oito plantas de repolho. Além da adubação verde, conforme descrito abaixo, na ocasião do transplantio, foi realizada a adubação de base com 3,5 $\mathrm{Mg} \mathrm{ha}^{-1}$ de esterco bovino curtido (base seca) com $1,6 \%$ de N. Os demais tratos culturais consistiram do controle manual das ervas espontâneas, aos 30 dias após o transplantio do repolho.

Três dias após o transplantio do repolho, realizouse a coleta das espécies vegetais marcadas com ${ }^{15} \mathrm{~N}$, que estavam com 70 DAS. Nessa ocasião, a parte aérea das leguminosas e do sorgo foram cortadas rente ao substrato e picotadas em fragmentos de cerca de $20 \mathrm{~cm}$. Posteriormente, foram retiradas quatro amostras de cada espécie, para a determinação de matéria seca, de átomos de ${ }^{15} \mathrm{~N}$ em excesso (Ramos et al., 2001) e de $\mathrm{N}$ total (Alves et al., 1994).

A palhada de adubo verde foi aplicada em cobertura nos canteiros com repolho. Na ocasião da aplicação da palhada, três dias após o transplantio do repolho, foram utilizados cinco tratamentos, distribuídos em blocos ao acaso, e quatro repetições. Os tratamentos consistiram de palha fresca de feijão-de-porco, marcada com $1,4039{ }^{15} \mathrm{~N}$ em excesso; palha fresca de mucuna-cinza, marcada com $1,0572{ }^{15} \mathrm{~N}$ em excesso; palha fresca de sorgo, marcada com 1,9740 ${ }^{15} \mathrm{~N}$ em excesso; mistura das palhas de mucuna, feijão-de-porco e sorgo à proporção de 1:1:1 (M+FP+SO), marcada com $1,1849{ }^{15} \mathrm{~N}$ em excesso (marcação da mistura); e controle sem adubação verde. Para os tratamentos com adubação verde, foram utilizadas doses equivalentes a $25 \mathrm{Mg} \mathrm{ha}^{-1}$ de matéria fresca. Isso correspondeu a 4,85, 5,15, 4,24 e 4,49 $\mathrm{Mg} \mathrm{ha}^{-1}$ de matéria seca de mucuna, feijãode-porco, sorgo e mistura $(\mathrm{M}+\mathrm{FP}+\mathrm{SO})$, respectivamente.

A recuperação do $\mathrm{N}$ derivado do adubo verde no sistema solo-planta, na ocasião da colheita do repolho, foi realizada por meio de amostragens de plantas (repolho e vegetação espontânea), resíduos dos adubos verdes e solo. Foram coletadas quatro plantas de repolho (parte aérea e raiz), 75 dias após o transplantio, na área central de cada parcela. Também foram coletados resíduos das coberturas e plantas espontâneas, de uma área delimitada por um quadrado de $25 \times 25 \mathrm{~cm}$, e uma amostra de solo da profundidade de $0-6 \mathrm{~cm}$ e $6-20 \mathrm{~cm}$ por parcela. Para a coleta das amostras de solo, foi utilizado um anel de aço inox com $10 \mathrm{~cm}$ de diâmetro.

As amostras da camada de $0-6 \mathrm{~cm}$ foram passadas em peneiras de 8 e $4 \mathrm{~mm}$. Todo material passou pela peneira de $8 \mathrm{~mm}$. O material passado e o retido na peneira de $4 \mathrm{~mm}$ foi seco ao ar e, posteriormente, preparado para a determinação de ${ }^{15} \mathrm{~N}$ e $\mathrm{N}$ total (Ramos et al., 2001). As amostras da camada de 6-20 cm foram apenas destorroadas, secas ao ar e preparadas para as análises.

O nitrogênio no solo, proveniente da palhada de adubo verde (NsoloAV), foi calculado de acordo com a equação NsoloAV $\left(\mathrm{kg} \mathrm{ha}^{-1}\right)=\left[{ }^{15} \mathrm{~N}\right.$ no solo $(\%) /{ }^{15} \mathrm{~N}$ no adubo verde (\%)] x $\mathrm{N}$ total na camada de solo $\left(\mathrm{kg} \mathrm{ha}^{-1}\right)$.

O nitrogênio no repolho, proveniente da palhada de adubo verde (NrepAV), foi calculado de acordo com as equações NrepAV $(\%)=\left[{ }^{15} \mathrm{~N}\right.$ no repolho $(\%) /{ }^{15} \mathrm{NAV}$ (\%)]100 e NrepAV $\left(\mathrm{kg} \mathrm{ha}^{-1}\right)=[\operatorname{NrepAV}(\%) / 100] \times \mathrm{N}$ total no repolho $\left(\mathrm{kg} \mathrm{ha}^{-1}\right)$.

A eficiência de recuperação de $\mathrm{N}$ do adubo verde pela planta do repolho (ER) foi calculada por $\mathrm{ER}(\%)=\left[\mathrm{NrepAV}\left(\mathrm{kg} \mathrm{ha}^{-1}\right) / \mathrm{NAV}\left(\mathrm{kg} \mathrm{ha}^{-1}\right)\right] 100$, em que, NAV é a quantidade de $\mathrm{N}$ aplicada à cultura do repolho em forma de adubo verde $\left(\mathrm{kg} \mathrm{ha}^{-1}\right)$.

Os resultados foram submetidos à análise de variância, e as médias foram comparadas pelo teste de Tukey, a $5 \%$ de probabilidade.

\section{Resultados e Discussão}

O nitrogênio recuperado na biomassa do repolho e proveniente do adubo verde (NrepAV) foi significativamente maior no tratamento com feijão-de-porco, que apresentou ER de 16\% (Tabela 1). O repolho cultivado no tratamento com gramínea (sorgo) apresentou menor NrepAV, em razão dos menores valores de NAV; contudo, esse tratamento proporcionou ER semelhante aos tratamentos com mucuna e com mistura de palhadas.

A eficiência do $\mathrm{N}$ derivado do feijão-de-porco, no presente trabalho, foi igual à eficiência obtida por Cueto-Wong et al. (2001) para o $\mathrm{N}$ derivado de alfafa e ervilha na cultura do sorgo, em condições de casa de vegetação. Valores similares também foram encontrados por Silva et al. (2006), que estudaram a transferência do $\mathrm{N}$ de $C$. juncea para o milho e 
observaram que a eficiência variou de 12 a $17 \%$, em consequência da dose utilizada. Em condições de casa de vegetação, Ambrosano et al. (2009) estudaram a transferência do $\mathrm{N}$ da mucuna-preta e da $C$. juncea para a cultura do milho e encontraram valores de ER de até 35\%. Ambrosano et al. (2011) encontraram ER de 19 a 21\% para cana-de-açúcar, tendo considerado duas safras, em sistema de pré-cultivo com $C$. juncea.

A semelhança entre as ER da mucuna-cinza e do sorgo (Tabela 1) não era esperada, uma vez que gramíneas apresentam alta relação C:N e, consequentemente, menor taxa de liberação de nutrientes que leguminosas. Gama-Rodrigues et al. (2007) relatam relação inversa entre relação $\mathrm{C}: \mathrm{N}$ e liberação de nutrientes por ação dos microrganismos decompositores, em diversas plantas de cobertura.

Uma possível explicação para a maior ER com uso de feijão-de-porco, em comporação ao uso de mucuna, pode ser o fato de a mucuna-cinza apresentar relação $\mathrm{C}: \mathrm{N}$ menor (Tabela 1). Esse fato poderia contribuir para uma mineralização mais rápida do $\mathrm{N}$ e liberação desse nutriente antes do completo desenvolvimento do sistema radicular do repolho. Essa assincronia entre liberação e capacidade de absorção pela planta pode, portanto, ter resultado nas menores ER com o uso de mucuna. Entretanto, observa-se que, na colheita do experimento, o tratamento com mucuna-cinza não apresentou quantidade de $\mathrm{N}$ no solo proveniente do adubo verde (NsoloAV) significativamente menor do que o tratamento com feijão-de-porco, em nenhuma das profundidades avaliadas (Tabela 2). Isso indica que parte do $\mathrm{N}$ derivado da mucuna foi perdido pelo sistema solo-planta. Aita et al. (2004) estudaram a dinâmica

Tabela 1. Nitrogênio total do adubo verde aplicado (NAV), relação $\mathrm{C}: \mathrm{N}$ dos adubos verdes, $\mathrm{N}$ da palha de adubo verde recuperado no repolho (NrepAV), e eficiência de recuperação do nitrogênio, derivado do adubo verde, pelo repolho (ER) cultivado sob diferentes tipos de palha de adubo verde ${ }^{(1)}$.

\begin{tabular}{lcccccc}
\hline Tratamento & \multicolumn{2}{c}{ Adubo verde } & & \multicolumn{2}{c}{ Repolho } \\
\cline { 2 - 3 } \cline { 5 - 6 } \cline { 5 - 6 } & & NAV $\left(\mathrm{kg} \mathrm{ha}^{-1}\right)$ & Relação C:N & & NrepAV $\left(\mathrm{kg} \mathrm{ha}^{-1}\right)$ & ER(\%) \\
\hline Mucuna & 149 & 14,0 & & $13,42 \mathrm{~b}$ & $9 \mathrm{~b}$ \\
Feijão-de-porco & 127 & 17,4 & & $19,79 \mathrm{a}$ & $16 \mathrm{a}$ \\
Sorgo & 42 & 43,5 & & $3,36 \mathrm{c}$ & $8 \mathrm{~b}$ \\
M+FP+S & 92 & 21,0 & & $6,71 \mathrm{c}$ & $7 \mathrm{~b}$ \\
\hline $\mathrm{CV}(\%)$ & - & - & & 22,45 & 21,41 \\
\hline
\end{tabular}

${ }^{(1)}$ Médias seguidas de letras iguais, nas colunas, não diferem entre si pelo teste de Tukey, a 5\% de probabilidade. $\mathrm{M}+\mathrm{FP}+\mathrm{S}$, mucuna + feijão-de-porco + sorgo à proporção de 1:1:1. de $\mathrm{N}$ após aplicação de diferentes tipos de palhada e observaram que o tratamento com ervilhaca, que apresentava relação $\mathrm{C}: \mathrm{N}$ igual à da mucuna-cinza, foi o que apresentou maior potencial para a lixiviação de $\mathrm{N}$, em comparação aos tratamentos com maior relação C:N.

$\mathrm{O}$ feijão-de-porco tem sido destacado entre as leguminosas quanto à sua capacidade de fornecer $\mathrm{N}$ para as culturas subsequentes. Gama-Rodrigues et al. (2007) estudaram a decomposição de amendoim-forrageiro (Arachis pintoi), siratro (Macroptilium atropurpureum), cudzu tropical (Pueraria phaseoloides), braquiária [Urochloa brizantha (Syn. Brachiaria brizantha)] e feijão-de-porco, e observaram que este último apresentou resíduo com maior taxa de liberação de $\mathrm{N}, \mathrm{P}, \mathrm{Ca}$ e Mg.

$\mathrm{Na}$ camada de solo de $0-6 \mathrm{~cm}$ de profundidade, independentemente do tamanho de agregado $(<4 \mathrm{~mm}$ ou $>4 \mathrm{~mm}$ ), o tratamento com palhada de feijão-de-porco apresentou significativamente maior quantidade de NsoloAV do que o tratamento com sorgo (Tabela 2).

Tabela 2. Nitrogênio total do solo, e $\mathrm{N}$ derivado da palha de adubo verde recuperado no solo (NsoloAV), nas camadas do solo de 0-6 cm (agregados passados ou retidos na peneira de $4 \mathrm{~mm})$ e 6-20 cm, no momento da colheita do repolho ${ }^{(1)}$.

\begin{tabular}{lcc}
\hline Tratamento & Nitrogênio total & NsoloAV \\
& - & Camada de $0-6 \mathrm{~cm}$, agregados $<4 \mathrm{~mm}$ \\
Controle & $319,2 \mathrm{a}$ & $-(2)$ \\
Mucuna & $366,3 \mathrm{a}$ & $16,2 \mathrm{ab}$ \\
Feijão-de-porco & $383,7 \mathrm{a}$ & $24,3 \mathrm{a}$ \\
Sorgo & $351,2 \mathrm{a}$ & $8,2 \mathrm{~b}$ \\
M+FP+SO & $278,0 \mathrm{a}$ & $16,1 \mathrm{ab}$ \\
\hline CV (\%) & 22,71 & 27,83 \\
\hline & Camada de 0-6 cm, agregados $>4 \mathrm{~mm}$ \\
Controle & $319,2 \mathrm{a}$ & - \\
Mucuna & $465,4 \mathrm{a}$ & $10,3 \mathrm{ab}$ \\
Feijão-de-porco & $429,4 \mathrm{a}$ & $14,0 \mathrm{a}$ \\
Sorgo & $430,9 \mathrm{a}$ & $04,9 \mathrm{~b}$ \\
M+FP+SO & $579,1 \mathrm{a}$ & $12,4 \mathrm{ab}$ \\
\hline CV (\%) & 18,62 & 36,13 \\
\hline & \multicolumn{1}{c}{ Camada de 6-20 cm } \\
Controle & $1976,86 \mathrm{a}$ & - \\
Mucuna & $1984,44 \mathrm{a}$ & $9,8 \mathrm{a}$ \\
Feijão-de-porco & $1820,70 \mathrm{a}$ & $7,8 \mathrm{a}$ \\
Sorgo & $1846,40 \mathrm{a}$ & $3,0 \mathrm{a}$ \\
M+FP+SO & $1973,00 \mathrm{a}$ & $5,5 \mathrm{a}$ \\
\hline CV (\%) & 8,79 & 48,99 \\
\hline (1)Médias seguidas de letras iguais, nas colunas, a diferentes profundidades \\
e tamanhos de agregados, não diferem entre si pelo teste de Tukey, a 5\% \\
de probabilidade. M+FP+SO, palhada de mucuna-cinza + feijão-de-porco \\
+ sorgo à proporção de 1:1:1. (2) Não calculado.
\end{tabular}


Na camada de solo de 6-20 cm de profundidade, não foi observada diferença significativa entre os tratamentos.

Ao se fazer um balanço de $\mathrm{N}$ no sistema solo-planta ( $\mathrm{N}$ aplicado - $\mathrm{N}$ recuperado no sistema), observa-se que, dos cerca de $150 \mathrm{~kg} \mathrm{ha}^{-1}$ de $\mathrm{N}$ aplicado com a adição de palhada no tratamento com mucuna-cinza, por exemplo, apenas $90 \mathrm{~kg} \mathrm{ha}^{-1}$ foram recuperados no sistema solo-planta (Figura 1). Os $60 \mathrm{~kg} \mathrm{ha}^{-1}$ de $\mathrm{N}$ não recuperados podem ter sido perdidos por lixiviação de nitrato para camadas com profundidade superior a $20 \mathrm{~cm}$ ou por volatilização de amônia. De acordo com Aita et al. (2001), leguminosas que apresentam rápida liberação do $\mathrm{N}$ após o seu manejo podem perder $\mathrm{N}$ no solo por lixiviação de nitrato, principalmente se ocorrerem chuvas intensas e não houver cultura capaz de absorver o $\mathrm{N}$ liberado. Assim, caso o sistema radicular do repolho ainda não esteja bem desenvolvido, no momento da liberação do $\mathrm{N}$ da leguminosa, ele poderá ser perdido da camada superficial do solo. Cueto-Wong et al. (2001) observaram presença de $\mathrm{N}$ derivado do adubo verde aplicado em cobertura até a camada de 30-60 $\mathrm{cm}$ de profundidade. Nos tratamentos com feijão-de-porco e de mistura das palhadas, o balanço de $\mathrm{N}$ no sistema solo-planta foi de -15 e $-25 \mathrm{~kg} \mathrm{ha}^{-1}$, respectivamente. No tratamento com palhada de sorgo, todo $\mathrm{N}$ aplicado foi recuperado no sistema solo-planta. Isso mostra que o $\mathrm{N}$ retido em material mais recalcitrante (maior relação $\mathrm{C}: \mathrm{N}$ ) permanece por mais tempo no sistema. O contrário foi observado para as leguminosas,

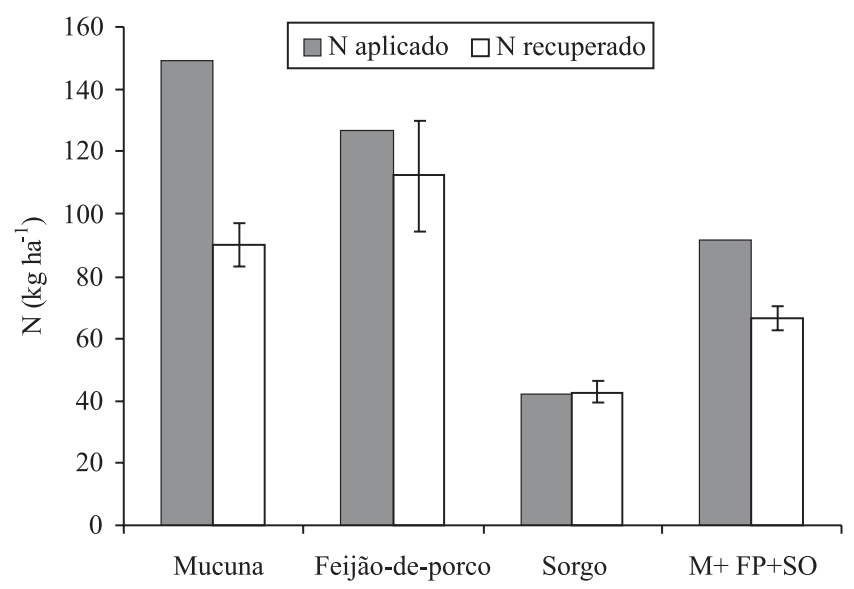

Figura 1. Nitrogênio aplicado em forma de palhada de adubo verde e nitrogênio recuperado no sistema solo-planta (repolho, plantas espontâneas e solo), após o cultivo de repolho, cultivar Seisho, sob manejo orgânico. $\mathrm{M}+\mathrm{FP}+\mathrm{SO}$, mistura de palhadas de mucuna-cinza + feijão-de-porco+sorgo à proporção de 1:1:1. em razão da facilidade com que o $\mathrm{N}$ é mineralizado em virtude da baixa relação C:N (Aita et al., 2004).

No tratamento com palhada de sorgo, $100 \%$ do $\mathrm{N}$ aplicado nessa forma foi recuperado no sistema solo-planta (Figura 1). Esse resultado era esperado, uma vez que, conforme mencionado anteriormente, a taxa de mineralização de gramínea é menor do que a das leguminosas, o que contribui para maior permanência do N no sistema. Esse resultado mostra que a técnica isotópica utilizada permitiu avaliar a dinâmica de $\mathrm{N}$ no sistema solo-planta. Todos os demais tratamentos apresentaram perda de $\mathrm{N}$ do sistema avaliado.

A dinâmica de $\mathrm{N}$ no sistema solo-planta variou em consequência do tipo de palhada de adubo verde utilizada. No tratamento com mucuna-cinza, apenas $60 \%$ do $\mathrm{N}$ aplicado foi recuperado no sistema solo-planta. (Figura 2). Cerca de 50\% do N aplicado foi encontrado nos resíduos da leguminosa e no solo $(0-20 \mathrm{~cm})$, e cerca de $10 \%$ na biomassa do repolho. No tratamento com feijão-de-porco, cerca de $90 \%$ do $\mathrm{N}$ aplicado foi recuperado no sistema solo-planta. A palhada dessa leguminosa, além de ter sido o tratamento que melhor

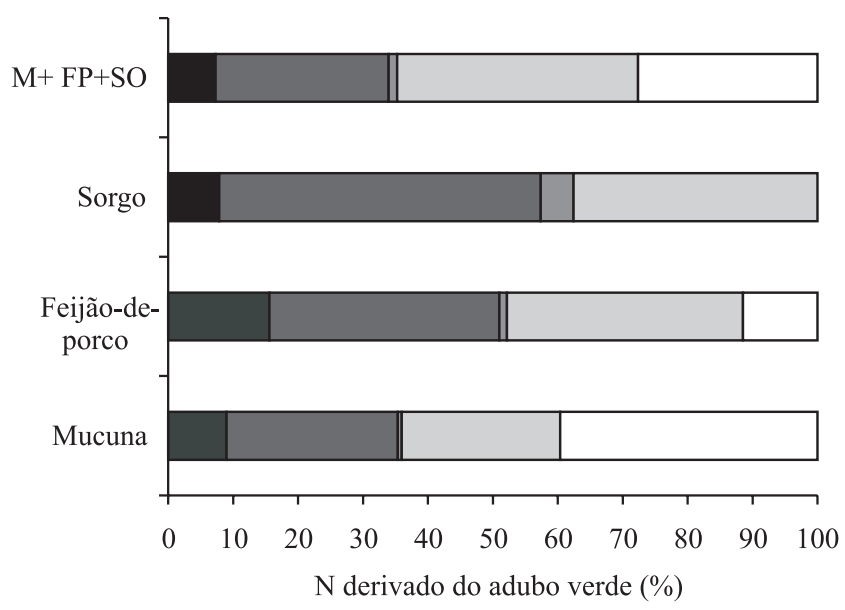

NrepAV $\square$ NresAV $\square$ NespAV $\square$ NsoloAV $\square$ N-não recuperado

Figura 2. Nitrogênio derivado da palha de adubo verde recuperado do repolho (NrepAV), $\mathrm{N}$ derivado de adubo verde recuperado no resíduo da palhada que permaneceu na superfície do solo (NresAV), $\mathrm{N}$ derivado de adubo verde recuperado nas plantas espontâneas (NespAV), $\mathrm{N}$ derivado de adubo verde recuperado no solo, na camada de $0-20 \mathrm{~cm}$ de profundidade (NsoloAV), e N não recuperado no sistema soloplanta (N-não recuperado) após o cultivo do repolho 'Seisho' sob manejo orgânico. $\mathrm{M}+\mathrm{FP}+\mathrm{SO}$, palhada de mucuna-cinza + feijão-de-porco+sorgo à proporção de 1:1:1. 
contribuiu para a nutrição nitrogenada do repolho, apresentou cerca de $70 \%$ do $\mathrm{N}$ aplicado nos resíduos e no solo, portanto com potencial para contribuir com a nutrição das plantas em cultivo sucessivo. Esses resultados corroboram os dados obtidos por Gama-Rodrigues et al. (2007), que observaram que o feijão-de-porco apresenta boa qualidade de resíduos em razão, principalmente, de seu teor de $\mathrm{N}$ e relação $\mathrm{C}: \mathrm{N}$, superiores aos de outras leguminosas e gramíneas estudadas pelos autores.

No que diz respeito à recuperação de $\mathrm{N}$ derivado do adubo verde, no solo, estudos desenvolvidos por Cueto-Wong et al. (2001) apontaram presença de N derivado do adubo verde na camada de 30-60 cm de profundidade, o que indica que a lixiviação influencia a taxa de recuperação de $\mathrm{N}$ no sistema solo-planta, principalmente quando estudada apenas a camada de 0-20 cm.

É importante observar que o tratamento com palhada de sorgo foi o que apresentou a maior proporção de $\mathrm{N}$ derivado da palhada nas plantas espontâneas (Figura 2).

Nas condições do estudo, não houve efeito da aplicação da palhada de adubo verde sobre as variáveis peso da "cabeça" e produtividade do repolho. O peso médio da "cabeça" foi de $1,7 \mathrm{~kg}$ por planta, e a produtividade média foi $72 \mathrm{Mg} \mathrm{ha}^{-1}$. A ausência de resposta à adubação verde pode ter ocorrido tanto pela elevada fertilidade do solo da área experimental, associada à adubação com esterco realizada no transplantio, como pelo pequeno número de plantas de repolho amostradas na ocasião da colheita. Seguindo a mesma tendência observada para produtividade, a quantidade de nitrogênio acumulada pela cultura do repolho (parte aérea e raiz) também não foi influenciada de forma significativa pela adubação verde. O repolho acumulou $168 \mathrm{~kg} \mathrm{ha}^{-1}$, em média, independentemente do tratamento.

A ausência de resposta do repolho à palhada dos adubos verdes, no que diz respeito à produtividade e à acumulação de $\mathrm{N}$, indica que, nas condições do experimento, o $\mathrm{N}$ não foi um fator limitante. Isso é confirmado pela alta produtividade no tratamento sem cobertura (controle) - de $68,87 \mathrm{Mg} \mathrm{ha}^{-1}$-, superior à obtida por Oliveira et al. (2005), nas mesmas condições edafoclimáticas. A produtividade obtida no presente estudo é similar à obtida por Maroeulli et al. (2010) com híbrido de repolho 'Astrus'.

\section{Conclusões}

1. A recuperação de nitrogênio no sistema solo-planta é influenciada pelo tipo de palhada de adubo verde utilizada, e a de feijão-de-porco é a que melhor contribui para a nutrição nitrogenada do repolho.

2. A taxa de recuperação, no sistema solo-planta, do N aplicado em forma de adubo verde, varia de 60 a $100 \%$.

\section{Agradecimentos}

À Fundação de Amparo à Pesquisa do Estado do Rio de Janeiro, ao Conselho Nacional de Desenvolvimento Científico e Tecnológico, e à Empresa Brasileira de Pesquisa Agropecuária, pelo apoio financeiro.

\section{Referências}

AITA, C.; BASSO, C.J.; CERETTA, C.A.; GONÇALVES, C.N.; DA ROS, C.O. Plantas de cobertura de solo como fonte de nitrogênio ao milho. Revista Brasileira de Ciência do Solo, v.25, p.157-165, 2001

AITA, C.; GIACOMINI S.J.; HÜBNER, A.P.; CHIAPINOTTO, I.C.; FRIES, M.R. Consorciação de plantas de cobertura antecedendo o milho em plantio direto. I - Dinâmica do nitrogênio no solo. Revista Brasileira de Ciência do Solo, v.28, p.739-749, 2004.

ALVES, B.J.R.; SANTOS, J.C.F. dos; BODDEY, R.M. Métodos de determinação do nitrogênio em solo e planta. In: HUNGRIA, M.; ARAÚJO, R.S. (Ed.). Manual de métodos empregados em estudos de microbiologia agrícola. Brasília: Embrapa-SPI, 1994. p.449-470. (Embrapa-CNPAF. Documentos, 46).

AMADO, T.J.C.; MIELNICZUK, J.; AITA, C. Recomendação de adubação nitrogenada para o milho no RS e SC adaptada ao uso de culturas de cobertura do solo, sob sistema plantio direto. Revista Brasileira de Ciência do Solo, v.26, p.241-248, 2002.

AMBROSANO, E.J.; TRIVELIN, P.C.O.; CANTARELLA, H.; AMBROSANO, G.M.B.; SCHAMMASS, E.A.; MURAOKA, T.; GUIRADO, N.; ROSSI, F. Nitrogen supply to corn from sunn hemp and velvet bean green manures. Scientia Agricola, v.66, p.386-394, 2009.

AMBROSANO, E.J.; TRIVELIN, P.C.O.; CANTARELLA, H.; AMBROSANO, G.M.B.; SCHAMMASS, E.A.; MURAOKA, T.; ROSSI, F. ${ }^{15} \mathrm{~N}$-labeled nitrogen from green manure and ammonium sulfate utilization by the sugarcane ratoon. Scientia Agricola, v.68, p.361-368, 2011.

AMBROSANO, E.J.; TRIVELIN, P.C.O.; CANTARELLA, H.C.; ROSSETTO, R.; MURAOKA, T.; BENDASSOLLI, J.A.; AMBROSANO, G.M.B.; TAMISO, L.G.; VIEIRA, F.C.; PRADA NETO, I. Nitrogen-15 labeling of Crotalaria juncea green manure. Scientia Agricola, v.60, p.181-184, 2003.

CARVALHO, D.F. de; SILVA, L.D.B. da; FOLEGATTI, M.V.; COSTA, J.R.; CRUZ, F.A. da. Avaliação da evapotranspiração 
de referência na região de Seropédica-RJ, utilizando lisímetro de pesagem. Revista Brasileira de Agrometeorologia, v.14, p.97-105, 2006.

CLAESSEN, M.E.C. (Org.). Manual de métodos de análise de solo. 2.ed. rev. atual. Rio de Janeiro: Embrapa-CNPS, 1997. 212p. (Embrapa-CNPS. Documentos, 1).

CUETO-WONG, J.A.; GULDAN, S.J.; LINDEMANN, W.C.; REMMENGA, M.D. Nitrogen recovery from $15 \mathrm{~N}$-labeled green manures: I. Recovery by forage sorghum and soil one season after green manure incorporation. Journal of Sustainable Agriculture, v.17, p.27-42, 2001.

DE-POLLI, H.; GUERRA, J.G.M.; ALMEIDA, D.L. de; FRANCO, A.A. Adubação verde - parâmetros para avaliação de sua eficiência. In: CASTRO FILHO, C. de; MUZILLI, O. (Ed.). Manejo integrado de solos em microbacias hidrográficas. Londrina: IAPAR, 1996. p.225-242.

FILGUEIRA, F.A.R. Novo manual de olericultura: agrotecnologia moderna na produção de hortaliças. 2.ed. rev. ampl. Viçosa: UFV, 2003. 412p.

FONTANÉTTI, A.; CARVALHO, G.J. de; GOMES, L.A.A.; ALMEIDA, K. de; MORAES, S.R.G. de; TEIXEIRA, C.M. Adubação verde na produção orgânica de alface americana e repolho. Horticultura Brasileira, v.24, p.146-150, 2006.

FRANCO, A.A.; DOBEREINER, J. Especificidade hospedeira na simbiose com Rhizobium -feijão e influência de diferentes nutrientes. Pesquisa Agropecuária Brasileira, v.2, p.467-474, 1967.

GAMA-RODRIGUES, A.C. da; GAMA-RODRIGUES, E.F. da; BRITO, E.C. de. Decomposição e liberação de nutrientes de resíduos culturais de plantas de cobertura em Argissolo Vermelho-Amarelo na Região Noroeste Fluminense (RJ). Revista Brasileira de Ciência do Solo, v.31, p.1421-1428, 2007.
LARA CABEZAS, W.A.R.; ALVES, B.J.R.; URQUIAGA CABALLERO, S.S.; SANTANA, D.G. de. Influência da cultura antecessora e da adubação nitrogenada na produtividade de milho em sistema plantio direto e solo preparado. Ciência Rural, v.34, p.1005-1013, 2004.

MAROUELLI, W.A.; ABDALLA, R.P.; MADEIRA, N.R.; OLIVEIRA, A.S. de; SOUZA, R.F. de. Eficiência de uso da água e produção de repolho sobre diferentes quantidades de palhada em plantio direto. Pesquisa Agropecuária Brasileira, v.45, p.369-375, 2010.

OLIVEIRA, F.L. de; RIBAS, R.G.T.; JUNQUEIRA, R.M.; PADOVAN, M.P.; GUERRA, J.G.M.; ALMEIDA, D.J. de; RIBEIRO, R. de L.D. Desempenho do consórcio entre repolho e rabanete com pré-cultivo de crotalária, sob manejo orgânico. Horticultura Brasileira, v.23, p.184-188, 2005.

PERIN, A.; SANTOS, R.H.S.; URQUIAGA, S.; GUERRA, J.G.M.; CECON, P.R. Efeito residual da adubação verde no rendimento de brócolo (Brassica oleraceae L. var. Italica) cultivado em sucessão ao milho (Zea mays L.). Ciência Rural, v.34, p.1739-1745, 2004.

RAMOS, M.G.; VILLATORO, M.A.A.; URQUIAGA, S.; ALVES, B.J.R.; BODDEY, R.M. Quantification of the contribution of biological nitrogen fixation to tropical green manure crops and the residual benefit to a subsequent maize crop using ${ }^{15} \mathrm{~N}$-isotope techniques. Journal of Biotechnology, v.91, p.105-115, 2001.

SILVA, E.C. da; MURAOKA, T.; BUZETTI, S.; VELOSO, M.E. da C.; TRIVELIN, P.C.O. Aproveitamento do nitrogênio $\left({ }^{15} \mathrm{~N}\right) \mathrm{da}$ crotalária e do milheto pelo milho sob plantio direto em Latossolo Vermelho de Cerrado. Ciência Rural, v.36, p.739-746, 2006.

URQUIAGA, S.; ZAPATA, F. Manejo eficiente de la fertilización nitrogenada de cultivos anuales en América Latina y el Caribe. Porto Alegre: Genesis; Rio de Janeiro: Embrapa Agrobiologia, 2000. $110 \mathrm{p}$

Recebido em 30 de dezembro de 2010 e aprovado em 4 de maio de 2011 